\title{
The Formation of Fruit Quality in Cucumis sativus L.
}

\author{
Juping Zhang ${ }^{1 \dagger}$, Shengjun Feng ${ }^{1 \dagger}$, Jing Yuan ${ }^{2 \dagger}$, Chen Wang ${ }^{2}$, Tao $\mathrm{Lu}^{3}$, Huasen Wang ${ }^{1 *}$ \\ and Chao $\mathrm{Yu}^{1 *}$ \\ ${ }^{1}$ Collaborative Innovation Center for Efficient and Green Production of Agriculture in Mountainous Areas, College \\ of Horticulture Science, Zhejiang A\&F University, Hangzhou, China, ${ }^{2}$ State Key Laboratory of Subtropical Silviculture, \\ Laboratory of Plant Molecular and Developmental Biology, College of Forestry and Biotechnology, Zhejiang A\&F University, \\ Hangzhou, China, ${ }^{3}$ Institute of Vegetables and Flowers, Chinese Academy of Agricultural Sciences, Beijing, China
}

OPEN ACCESS

Edited by:

Pei Xu,

China Jiliang University, China

Reviewed by:

Zheng Li,

Northwest A\&F University, China Zhihui Chen,

University of Dundee, United Kingdom Tao Yao,

Oak Ridge National Laboratory (DOE), United States

*Correspondence:

Huasen Wang

wanghs@zafu.edu.cn

Chao Yu

yuch@zafu.edu.cn

tThese authors have contributed equally to this work

Specialty section:

This article was submitted to Crop and Product Physiology,

a section of the journa

Frontiers in Plant Science

Received: 23 June 2021

Accepted: 18 August 2021

Published: 23 September 2021

Citation:

Zhang J, Feng S, Yuan J, Wang C, Lu T, Wang H and Yu C (2021) The Formation of Fruit Quality

in Cucumis sativus $L$.

Front. Plant Sci. 12:729448.

doi: 10.3389/fp/s.2021.729448
Cucumber is one of the most widely grown vegetables in China and an indispensable fresh fruit in the diet. With the development of society, the demand of people for cucumber quality is higher and higher. Therefore, cultivating high-quality cucumber varieties is one of the main goals of cucumber breeding. With the rapid development of biotechnology such as molecular marker, cucumber quality control network is becoming clear. In this review, we describe the formation mechanism of cucumber fruit quality from three aspects: (1) the commercial quality of cucumber fruit, (2) nutritional quality formation, and (3) flavor quality of cucumber fruit. In addition, the determinants of cucumber fruit quality were summarized from two aspects of genetic regulation and cultivation methods in order to provide ideas for cucumber researchers and cultivators to improve fruit quality.

Keywords: cucumber, fruit quality, QTLs, spine, bitterness, grafting

\section{INTRODUCTION}

Cucumber (Cucumis sativus L.) is an annual herbaceous climbing fruit vegetable that belongs to the Cucurbitaceae family and originates from the tropical rainforest in the southern foot of the Himalayas. According to its geographical locations, it can be categorized into four groups such as the Indian group, the Eurasian group, the East Asian group, and the Xishuangbanna group (Qi et al., 2013). In China, cucumber can be subdivided into two geographic groups, such as the northern China group with dark green, dense spines and warts on fruits, and the southern China group with light green, sparse spines and warts on fruits (Jiang et al., 2015). Cucumber is an economically important crop in the world. Its fruits are fragrant and delicious with nutrient enrichment that can be consumed in fresh or processed into pickles. In addition, its fruits are also used in beauty products. However, with the constantly change in the cultivation environment and techniques, and the ever-rising living standards of people, the cucumber fruit quality is becoming much more concerned by the consumers.

With the continuous work on the formation of cucumber fruit quality by various research groups in recent years, some of the influencing factors and regulation mechanism of the formation of cucumber fruit quality can be understood now in a more in-depth and thorough manner. This review attempted to summarize the recent advances in the studies on the formation of cucumber fruit quality through physiological and molecular biological approaches in order to provide insights for further research studies on the formation of fruit quality of cucumber and other melons. 
Fruit quality in cucumber can be defined by three aspects, namely, commercial quality, nutrient quality, and flavor quality (Lv et al., 1992). The commercial quality in cucumber contains the fruit size and shape, fruit spine characteristics (color, size, and density), fruit skin characteristics (color, ridges, and speckles), and flesh characteristics (color) (Wang et al., 2007; Lu et al., 2015; Zhang et al., 2016; Zhang C. et al., 2019). Fruit size and shape are the two most obvious appearances of quality traits in cucumber, which had become one of the criterions for breeders to select high fruit quality cultivars. The external fruit qualities, such as the fruit skin and spine color, the presence or absence of the wax on the cucumber surface, and the number, shape, size, distribution, and density of fruit spines (trichomes on cucumber fruit are called spines), are also important fruit quality traits for cucumber production (Choi et al., 2013; Li et al., 2013; Chen et al., 2014; Liu X. et al., 2016). In the late 1980s, the bloomless cucumber fruits are popular in Japan due to their distinct shiny appearance (Ohara et al., 2006). Besides, the character of spines could also have a big influence on consumer preference. For example, people in Europe prefer cucumber without spines, whereas people in Asia like cucumber with spines (Chen et al., 2014). Furthermore, epicuticular wax, which acts as the outermost barrier between the plants and their environment, is also one of the significant commercial quality traits in cucumber that can play significant roles in protecting the tissues against various biotic and abiotic stress (Samuels et al., 2008). Moreover, fruit flesh color that varies from white to green or yellow to orange is also an important fruit quality trait that influences the preference of consumers (Cuevas et al., 2010).

On the other hand, nutrition elements, such as soluble solids, vitamins, and minerals, constitute the nutrient quality in cucumber. In addition, flavor quality in cucumber, for one reason, contains all of the volatile compounds from cucumber, and for another reason, it is related to the non-volatile flavor substances (Kemp et al., 1974; Malundo et al., 1995). Ever since the 1960s, there have had research studies on the flavor of cucumber (Forss et al., 1962). Nowadays, there are more and more research studies on fruit flavor, which would help us to improve the fruit quality of cucumber.

\section{GENETIC REGULATION OF FRUIT QUALITY IN CUCUMBER}

\section{Genetic Regulation of Commercial Quality in Cucumber}

Cucumber commercial quality is determined mainly by its fruitrelated traits. The genes related to the commercial quality traits of cucumber fruits are shown in Figure $\mathbf{1}$ and Table $\mathbf{1}$. The ability of cucumber to produce large fruits is believed to have been evolved through long time domestication of wild cucumber, and Cucumis sativus L. var. hardwickii is regarded as the ancestor of cultivated cucumber. Its fruit is small and round and about $3-5 \mathrm{~cm}$ long. In addition, it has large amounts of spines on its epidermis. It is so bitter that it is difficult to eat (Sebastian et al., 2010; Yang et al., 2012). Nowadays, the fruit length of widely cultivated cucumber is about 10$30 \mathrm{~cm}$, and the fruit shape has also become oblong, which has shown great variation compared with its ancestors. Besides, based on the whole genome sequencing and the construction of the high-resolution genetic map, we have gained a clearer understanding of the genetic mechanism of formation of fruit quality during their domestication processes (Huang et al., 2009; Qi et al., 2013).

\section{The Size and Shape of Cucumber Fruits}

Fruit size and shape, especially fruit length, are important fruit traits during cucumber domestication and diversifying selection. Wenzel et al. (1995) first identified the overall information of gene regulation on the cucumber fruit length, diameter, and other genetic traits. Yuan et al. (2008) constructed a 257-point genetic linkage map and found 78 quantitative trait locus (QTLs) related to fruit weight, fruit length, fruit diameter, and other four fruit-related traits, which can be used to conduct markerassisted selection in cucumber breeding. Bo et al., also detected several QTLs of cucumber fruit-related traits, including five fruit length-related QTLs (fl1.1, fl3.1, fl4.1, fl6.1, and $f l 7.1$ ), three fruit diameter-related QTLs $(f d 1.1, f d 4.1$, and $f d 6.1)$, and three fruit weight-related QTLs $(f w 2.1, f w 4.1$, and $f w 6.1)$. At the same time, they also found that the chromosomal rearrangements of cucumber ancestors between wild and cultivated cucumbers were mainly concentrated on chromosomes 4, 5, and 7 (Bo et al., 2015). Besides, Cheng et al. (2010) and Wang et al. (2014) also found 5 fruit length ( $\mathrm{Fl})$-related QTLs that were distributed in chromosome 1, 4, and 6 and 4 stalk length (Fsl)-related QTLs that were located on chromosome 3,4 , and 6 , respectively.

The enzyme 1-aminocyclopropane-1-carboxylic acid synthase (ACS) in the process of plant hormone ethylene synthesis plays an important role in cucumber sex determination. The genes involved in this process include CsACS1G (Kamachi et al., 1997), CsACS2 (Knopf and Trebitsh, 2006; Li et al., 2009), and CsACS11 (Boualem et al., 2015). Among them, the CsACS2 mutation makes cucumber produce a bisexual flower phenotype. CsACS2 gene was eliminated in addition to the above functions, and it is also related to the length of the cucumber fruit. Boualem et al. (2009) proved that an allele of CsACS2 co-segregated with the M (andromonoecious) locus, resulting in a round fruit phenotype after the gene mutation. Subsequently, Tan et al. (2015) further studied through fine mapping and found that another allele mutation of CsACS2 caused the cucumber to appear a long fruit phenotype. Later, Pan et al. (2017) found that round fruit shape in WI7239 cucumber was controlled by two interacting quantitative trait loci, such as FS1.2 and FS2.1, and demonstrated that FS2.1 may encode a homolog of tomato fruit shape gene SUN. They also identified a FS5.2 QTL in Xishuangbanna cucumber that has great significance on round fruit determination (Pan et al., 2017). Besides, Zhao et al. (2019) further demonstrated that among the QTLs that have putative functions in regulating cucumber fruit length, a gain-of-function allele $C s F U L 1^{A}$ can prevent the accumulation of auxin by inhibiting the expression of its transporters PIN-FORMED1 (PIN1) and PIN7. This further analyzes the molecular mechanism of auxin regulating cucumber fruit development. 


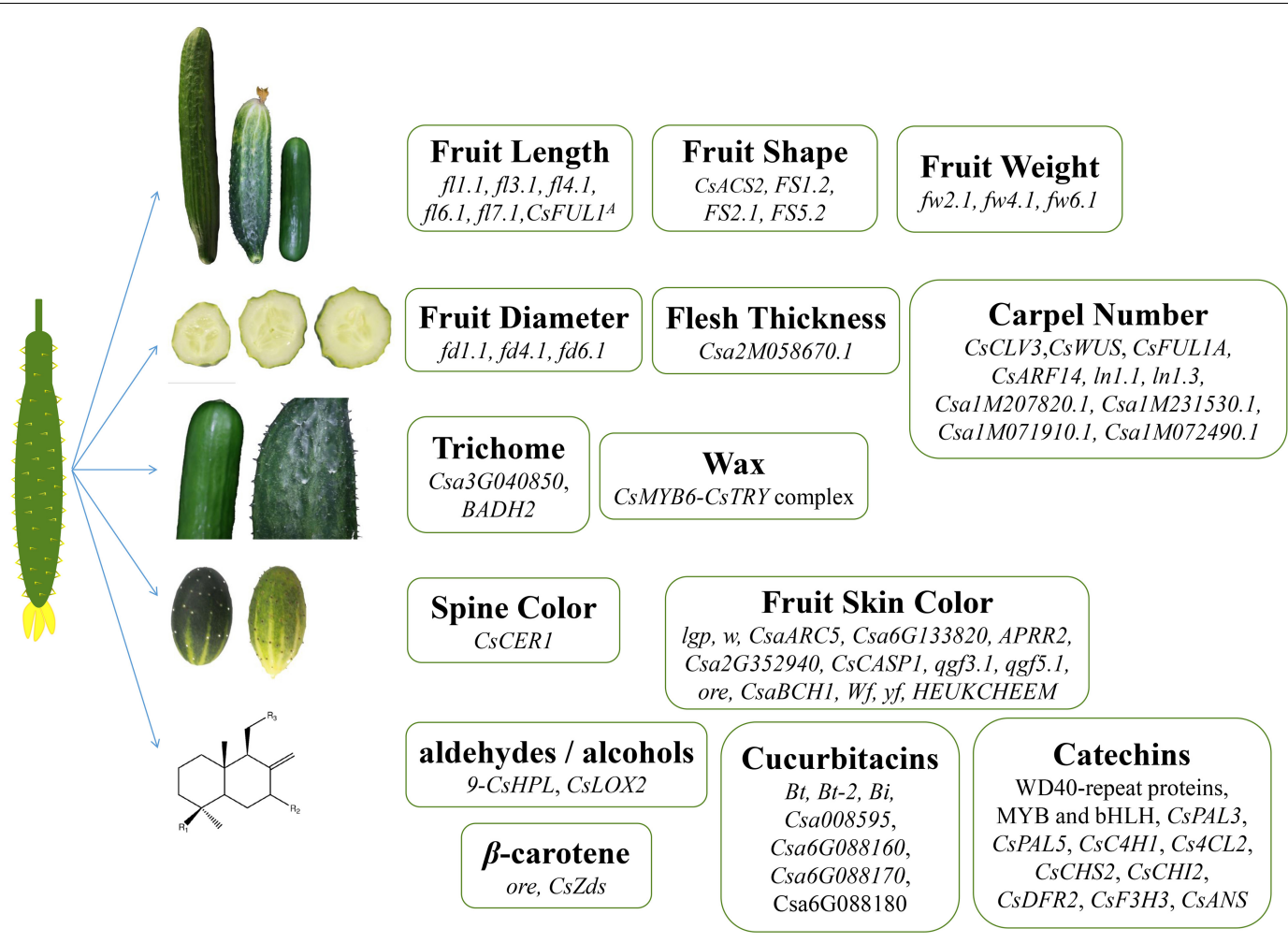

FIGURE 1 | Genes related to cucumber fruit quality. Genes regulating fruit length, fruit shape, weight, diameter, thickness, carpel number, trichome, wax, spine color, and synthesis of secondary metabolite in cucumber.

\section{The Carpel Number and Flesh Thickness of Cucumber Fruits}

In addition, factors that affect important fruit characteristics such as cucumber fruit shape, size, and internal quality also include the carpel number and the thickness of fruit flesh. The expression of $\mathrm{CsCLV3}$ in cucumber was negatively correlated with the number of carpels. CsCLV3 and CsWUS act as negative regulators and positive regulators of changes in carpel number, respectively, and CsWUS can be directly combined with the promoter of CsCLV3 to activate its expression. CsFUL1 ${ }^{A}$ overexpression plants showed increased petals and carpels. Through the interaction of CsARF14 and CsWUS, auxin can also participate in the change of cucumber carpel number (Che et al., 2020). The QTL mapping of Xishuangbanna cucumber revealed that $\ln 1.1$ and $\ln 1.3$ located on chromosome 1 are the main QTLs controlling multi-ventricular traits. At the same time, two genes, namely, Csa1M207820.1 and Csa1M231530.1, involved in plant hormone signal transduction and two genes, namely, Csa1M071910.1 and Csa1M072490.1, related to WD40 repeat protein are predicted as candidate genes (Zhang et al., 2015). By combining the separation and segmentation analysis with the sequencing of amplified fragments of specific lengths, the genes that regulate the pulp thickness of cucumber fruit were finely mapped, and the quantitative trait locus that controls the pulp thickness was located in the interval of about $0.19 \mathrm{Mb}$ on chromosome 2. This $0.19-\mathrm{Mb}$ region predicts and recognizes 20 genes, among which there is a 4 bp deletion mutation in the promoter region of the candidate gene Csa2M058670.1 (a protein-lysine methyltransferase, PKMT), which may lead to the loss of its activity in the thin fruit line. This suggests that Csa2M058670.1 may be a candidate gene for controlling cucumber pulp thickness (Xu et al., 2015). Csa2M058670.1 belongs to the same subfamily as At2g18850, and the latter is related to the cell division and growth process of Arabidopsis (Horvath et al., 2003). At present, there are too many factors affecting the thickness of pulp and the number of ventricles in cucumber, and these two traits are easily affected by the environment, so a consistent conclusion has not yet been reached.

\section{The Color of the Flesh and Skin of Cucumber Fruit}

The colors of the fruit flesh and skin are also significant commercial quality traits in cucumber that have obvious influences on the choice of the consumers. Fruit color was determined by the regulation of pigment in the plants, and chlorophylls were declared to be the main factor to determine the fruit skin color (Egea et al., 2010). In cucumber, five genes controlled fruit skin color, such as dark green $(D G)$, green $(d g)$, yellow green $(y g)$, light green $(\lg p)$, and white $(w)$ peeling genes (Pierce and Wehner, 1990; Dong et al., 2012). Now, the fruit light green peel gene $\lg p$ and the white peel gene $w$ have been identified (Wehner et al., 2001; Dong et al., 2012). The mutation of CsaARC5 (ACCUMULATION AND REPLICATION OF CHLOROPLASTS 5), the ortholog 
TABLE 1 | Genes related to the commercial quality of cucumber fruits.

\begin{tabular}{|c|c|c|c|}
\hline Category & Traits & QTLs or Gene name & References \\
\hline \multirow[t]{24}{*}{ Commercial quality } & Fruit length & $f|1.1, f| 3.1, f|4.1, f| 6.1$, and $f \mid 7.1$ & Bo et al., 2015 \\
\hline & & CSFUL1 ${ }^{A}$ & Zhao et al., 2019 \\
\hline & Fruit diameter & $f d 1.1, f d 4.1$, and $f d 6.1$ & Bo et al., 2015 \\
\hline & Fruit weight & $f w 2.1, f w 4.1$, and $f w 6.1$ & Bo et al., 2015 \\
\hline & Fruit shape & CSACS2 & Tan et al., 2015 \\
\hline & & FS1.2, FS2.1, and FS5.2 & Pan et al., 2017 \\
\hline & Carpel number & CsCLV3, CsWUS, CsFUL1 ${ }^{A}$, and CsARF14 & Che et al., 2020 \\
\hline & & $\begin{array}{l}\ln 1.1, \ln 1.3, \text { Csa1M207820.1, } \\
\text { Csa1M231530.1, Csa1M071910.1, and } \\
\text { Csa1M072490.1 }\end{array}$ & Zhang et al., 2015 \\
\hline & Flesh thickness & Csa2M058670.1 & Xu et al., 2015 \\
\hline & Fruit skin color & $\lg p$ & Wehner et al., 2001 \\
\hline & & $w$ & Dong et al., 2012 \\
\hline & & CsaARC5 & Zhou et al., 2015 \\
\hline & & Csa6G133820 & Lun et al., 2016 \\
\hline & & APRR2 & Liu H. et al., 2016 \\
\hline & & Csa2G352940 and CsCASP1 & Hao et al., 2018 \\
\hline & & qgf3. 1 and $9 g f 5.1$ & Bo et al., 2019 \\
\hline & & ore & Bo et al., 2012 \\
\hline & & $\mathrm{CsaBCH} 1$ & Qi et al., 2013 \\
\hline & & $w f$ and $y f$ & Kooistra, 1971; Whalen, 2005; Lu et al., 2015 \\
\hline & & HEUKCHEEM & Zhang C. et al., 2019 \\
\hline & Spine color & CsCER1 & Wang et al., 2015 \\
\hline & Wax & CsMYB6-CsTRY complex & Yang et al., 2018 \\
\hline & Trichome & Csa3G040850 & Wei et al., 2016 \\
\hline & & $B A D H 2$ & Yundaeng et al., 2015 \\
\hline
\end{tabular}

gene of Arabidopsis ARC5, led to a light green fruit peel phenotype in cucumber (Zhou et al., 2015). Another Ycf54like protein-encoding gene Csa6G133820 can also determine the formation of light green fruits (Lun et al., 2016). Besides, a single-nucleotide insertion on APRR2 disturbed the chlorophyll accumulation and chloroplast development so that leading to a white fruit color in cucumber (Liu H. et al., 2016). Identification of cucumber yellow green peel-related genes and research studies on their regulation mechanism have also progressed greatly in recent years. Research studies on a cucumber yellow green peel mutant $(y g p)$ identified a Csa2G352940 gene, encoding a MYB36 transcription factor, functioned to regulate a yellow green peel determination in cucumber. This study also revealed that CsMYB36 may interact with the peel color development-related genes, such as Casparian strip (CsCASP1) and pigment synthesis protein (CsMYC2), to regulate yellow green peel determination in cucumber (Hao et al., 2018).

Besides fruit skin color, chlorophylls can also influence the formation of flesh color. Bo et al. (2019) revealed that two QTLs, qgf3.1 and $q g f 5.1$, can function together in regulating the formation of green fruit flesh in cucumber. When cucumber fruits developed to the mature stage, their flesh color changed from green to yellow or green to orange. High $\beta$-carotene content was demonstrated to be the main reason for cucumber to form fruits with orange flesh color, and further genetic analysis demonstrated that the quantity of $\beta$-carotene was controlled by the orange endocarp (ore) gene (Bo et al., 2012) and CsaBCH1 (Qi et al., 2013). Cucumber fruits with white flesh and yellow flesh were proven to be controlled by two genes, $w f$ and a single recessive gene named $y f$, respectively (Kooistra, 1971; Whalen, 2005; Lu et al., 2015). The study on the color of cucumber flesh and skin will help to promote the breeding process of cucumber with a different color.

\section{External Quality of Cucumber Fruits}

Several genes and transcription factors are involved in the regulation of the external quality of cucumber fruits. Zhang C. et al. (2019) found that spine color was regulated by the HEUKCHEEM gene, mutations in HEUKCHEEM leading to a white spine in cucumber. Wang et al. (2015) revealed that CsCER1 significantly influenced the biosynthesis of alkane so that further influenced the wax synthesis of cucumber, and CsCER1 overexpression lines showed more wax crystallization phenotypes, whereas its RNA interference (RNAi) lines exhibited fewer wax crystallizations. Liu et al. (2018) analyzed 91 NAC gene homologs in cucumber and identified 13 NAC genes that can control fruit spine development. Yang et al. (2018) found that CsMYB6 and CsTRY can negatively regulate the trichome initiation in cucumber and revealed that CsMYB6 functions the upstream of CsTRY and that they can also form CsMYB6CsTRY complex to function together in this progress. These results provide a reference for the cultivation of non-spiny and prickly cucumbers. 


\section{Genetic Regulation of Flavor Quality in Cucumber}

Research studies on flavor quality have become popular in recent years. Foods with good or special tastes will increase the pleasure in people and influence the digestion in people and absorption of nutrients (Beaulieu and Lea, 2006). The genes contributed to the flavor quality traits of cucumber fruits are shown again in Figure 1 and Table 2. It is confirmed that the degradation of linoleic acid and linolenic acid occurred rapidly after the disruption of cucumber tissues and gave rise to the flavor of fresh cucumber (Ligor and Buszewski, 2008).

\section{The Scent of Cucumber Fruits}

Aldehydes and alcohols are thought to mainly contribute to the fresh cucumber scent (Kemp et al., 1974; Hatanaka et al., 1975; Palma-Harris et al., 2001; Ligor and Buszewski, 2008; Hao et al., 2013). Forss et al. (1962) first isolated 2,6-nonadienal from cucumber. Subsequently, Schieberle et al. (1990) found that $(E, Z)-2,6$-nonadienal mainly caused the flavor of cucumbers with fresh cucumber odor and identified (E)-2-nonenal as the second important odor compound in cucumber. Since six-carbon (C6) and nine-carbon (C9) aldehydes play an important role in flavor during fruit development, changes in volatile substances in developing cucumber fruits were investigated in two Cucumis sativus L. lines (No. 26 and No. 14). C6 aldehyde content was higher during the early stages, whereas the C9 aldehyde content was higher during the latter stages in both lines (Chen et al., 2015). Lipoxygenase (LOX) and hydroperoxide lyase (HPL) are the two key pre-regulatory factors in the synthesis of cucumber aldehydes. Thereinto, the expression patterns of 9-CsHPL are similar to the trend of $\mathrm{C} 9$, and the expression of CsLOX2 is also significantly correlated with changes in C9 aldehyde aroma content (Liu, 2018; Wei, 2018). Subsequently, Wei et al. (2016) analyzed 85 volatile chemicals in 23 different tissues of cucumber and further found that TPS15 (encoded by Csa3G040850) mediated the biosynthesis of volatile terpenoid in the fruit tissues, which will promote future research studies on the physiological function of volatiles and improve the cucumber flavor breeding. Except for fresh cucumber odor, Yundaeng et al. (2015) also found a special pandan (Pandanus amaryllifolius), like fragrance in PK2011T202 (PKT) cucumber cultivar in Thailand. They further found that 2-acetyl-1-pyrroline (2AP) generated this fragrance, and a betaine aldehyde dehydrogenase 2 (BADH2) mutant caused the biosynthesis of $2 \mathrm{AP}$ so that produced the pandan-like fragrance in PKT (Yundaeng et al., 2015). Two cucumber accessions, PKT and 301,176 (301), an inbred line from Clover Seed Company, Hong Kong, possessing no fragrance, were used to determine the mode of inheritance of these recessive fragrance traits and each controlled by a specific gene (Pramnoi et al., 2013).

\section{The Bitterness of Cucumber Fruits}

The bitterness of cucumber fruits is also of great popularity in the research study of flavor quality traits. Research studies have demonstrated that the Cucurbitacins ( $\mathrm{Ct}$ ) caused the bitterness in cucumber fruits (Rice et al., 1981; Balkema-Boomstra et al., 2003). Since the production of bitterness will lead to fatal losses in the sale of cucumbers, cultivating varieties of cucumbers without bitterness is of great significance for improving the efficiency of cucumber sales. Genetic mechanism of cucumber bitterness showed great complexity. Wehner et al. (2001) found that two dominant genes, Bt (bitter fruit) and Bt-2 (bitter fruit-2), controlled the bitterness of cucumber. In addition, bi (bitterfree cotyledons) gene and the fruit bitterness need both $\mathrm{Bi}$ and Bt genes (Andeweg and Bruyn, 1959; Gu et al., 2004; Shang et al., 2014). Further research studies by Zhang et al. (2013) proved that the candidate gene of bi-1 is considered to be the terpene synthase gene named Csa008595. Besides, Shang et al. (2014) further demonstrated that Bt can regulate the biosynthesis of cucurbitacin $\mathrm{C}(\mathrm{CuC})$ in the cucumber fruits and identified 11 cucumber bitterness biosynthesis, regulation, and domestication-related genes. In addition, the biosynthetic pathway and main regulators of cucurbitacin in cucumber have also been identified. By applying a comparative genomic study, Zhou et al., reported that the independent mutations of the homologous transcription factor genes in the three cucurbits may lead to a significant reduction in fruit bitterness, which may be the reason for the convergence and domestication of bitter wild cucurbits. A syntenic gene cluster that regulates both the tissue-specific biosynthesis of cucurbitacin and the loss of bitter phenotypes associated with the fusion and domestication of wild cucurbits has also been reported in this study. They also found that Csa6G088160, Csa6G088170, and Csa6G088180 in cucumber can participate in the biosynthesis of cucurbitacin C (Zhou et al., 2016).

In addition to cucurbitacin, catechins are also one of the key factors that cause cucumber to produce astringency. $\mathrm{Xu}$ et al. (2019a) found that tryptophan-aspartate acid (WD40)-repeat protein, avian myeloblastosis viral oncogene homolog (MYB), and basic helix-loop-helix (bHLH) also play an important role in the biosynthesis of catechins. They further found that some genes related to phenylalanine ammonia lyase (PAL)CsPAL3 and CsPAL5, to cinnamate 4-hydroxylase (C4H)$\mathrm{CsC} 4 \mathrm{H1}$, to 4-coumarate-CoA ligase (4CL)-Cs4CL2, to chalcone synthase (CHS)-CsCHS2, to chalcone isomerase (CHI)-CsCHI2, to flavanone 3-hydroxylase (F3H)-CsF3H3, to dihydroflavonol 4reductase (DFR)-CsDFR2, and to anthocyanidin synthase (ANS)CsANS are important regulators of catechin biosynthesis in cucumber fruits (Xu et al., 2019b). But there is currently no clear evidence on how catechins are regulated.

\section{Genetic Regulation of Nutrient Quality in Cucumber}

Qiao et al. (2005) reported that crude protein, Vitamin C (VC), soluble reductive sugar, soluble solids, and moisture were five important nutrient components in cucumber. Meanwhile, soluble solids can directly affect nutritional quality, with the greatest impact, while VC, soluble reducing sugars, and crude protein indirectly affect nutritional quality through soluble solids (Qiao et al., 2005). The genes related to the nutrient quality traits of cucumber fruits are shown in Figure 1 and Table 2. The heritability of the soluble sugar content of cucumber is higher, and the selection of early generation has a better effect on it 
TABLE 2 | Genes related to the nutrient quality and flavor quality of cucumber fruits.

\begin{tabular}{|c|c|c|c|}
\hline Category & Traits & QTLs or Gene name & References \\
\hline \multirow[t]{7}{*}{ Flavor quality } & Aldehydes/alcohols & 9-CsHPL & Liu, 2018 \\
\hline & & CsLOX2 & Wei, 2018 \\
\hline & Cucurbitacins & $B t, B t-2$, and $B i$ & $\begin{array}{l}\text { Andeweg and Bruyn, 1959; Wehner et al., 2001; Gu } \\
\text { et al., 2004; Shang et al., } 2014\end{array}$ \\
\hline & & Csa008595 & Zhang et al., 2013 \\
\hline & & $\begin{array}{l}\text { Csa6G088160, Csa6G088170, and } \\
\text { Csa6G088180 }\end{array}$ & Zhou et al., 2016 \\
\hline & Catechins & WD40-repeat proteins, MYB, and bHLH & Xu et al., 2019a \\
\hline & & 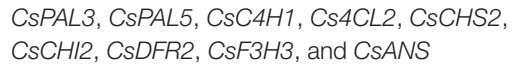 & Xu et al., 2019b \\
\hline \multirow[t]{2}{*}{ Nutrient quality } & $\beta$-carotene & ore & Bo et al., 2012 \\
\hline & & CsZds & Wang et al., 2012 \\
\hline
\end{tabular}

(Xu et al., 2001). Zhang et al. (2020) found that the relationship between soluble sugar and water is positively correlated, while ascorbic acid is negatively correlated with water and soluble sugar. Besides, the contents of $\beta$-carotene, a provitamin $A$, were also important nutrient qualities in cucumber, its contents in cucumber were regulated by an ore gene, and seven simple sequence repeat (SSR) markers were identified linking to the locus controlling $\beta$-carotene quantity (Bo et al., 2012). On this basis, Wang et al. (2012) used RACE technology to successfully clone the complementary DNA (cDNA) sequence of the $\zeta$-carotene dehydrogenase (ZDS) gene $(C s Z d s)$ and speculated that the gene may be related to the accumulation of $\beta$-carotene in cucumber fruits. However, there existed fewer genetic research studies on nutrient qualities in cucumber even until now, and further studies are needed to identify factors related to nutrient qualities formation in cucumber.

\section{PHYSIOLOGICAL REGULATION OF FRUIT QUALITY IN CUCUMBER}

\section{Physiological Regulation of Commercial Quality in Cucumber}

Cucumber plants usually have poorly developed root systems, rending them vulnerable to infection by various pests and diseases; thus, the cucumber growers have to apply various techniques to improve the commercial quality of cucumber fruits (Figure 2). Grafting was wildly used to improve the stress resistance in cucumber, which could also generate positive influences on improvement in their fruit commercial quality (King et al., 2008; Colla et al., 2013). Grafting can also influence the transcript expression levels in cucumber. For example, Zhang J. et al. (2019) found that compared to those self-rooted cucumber, the grafted cucumber showed a higher expression level of the Apetala2/ethylene-responsive factor (AP2/ERF)-type transcription factor CsWIN1, and CsWIN1 further promoted the expression of several key wax biosynthesis and transporter genes so that reflected a glossier appearance. Besides, the usage of plant growth regulators is also an effective measure to alter the fruit qualities in cucumber. Qian et al. (2018) found that N-(2-chloro-4-pyridyl)- $\mathrm{N}^{\prime}$-phenylurea (CPPU) treatment produced a positive effect on cucumber appearance for the increased flesh firmness. However, gibberellin A4 + A7 $(\mathrm{GA} 4+7)$ treatment reduced its commercial quality (Qian et al., 2018). Hypoxia treatment can inhibit the fresh weight of cucumber fruit. Under hypoxia stress, increasing the amount of exogenous calcium can increase the fresh weight of the fruit (He et al., 2018).

\section{Physiological Regulation of Flavor Quality in Cucumber}

Grafting not only affects the commercial quality of cucumbers but also affects the total amount of aroma substances and characteristic esters in the fruit (Pérez et al., 2002). Dong et al. (2013) found that the increased content of volatile substances such as acetaldehyde in the fruits of cucumbers grafted to pumpkins led to a decrease in the flavor and taste of the fruits. Zhao et al., found that compared with those selfgrafted cucumbers, the total content of alcohols, aldehydes, olefins, and acids increased of those cucumber plants that were grafted onto "Weisheng NO.1" (Cucurbita moschata hybrids) rootstock, so the flavor quality was significantly improved, while the cucumber plants grafted onto Cucurbita ficifolia rootstock showed the opposite trend. Grafting of different rootstocks will also significantly affect the expression of genes related to glycolysis, fructose metabolism, and $\alpha$-linolenic acid metabolism in the scion, thereby changing the flavor quality of grafted cucumbers (Zhao et al., 2018). Different grafting methods will also affect the flavor of cucumber fruits (Lee, 1994). Peng et al. (2010) comprehensively evaluated the sweetness, bitterness, astringency, moisture, and other aspects of cucumber fruit and found that the taste quality of cucumber after doublecut root grafting was the best, while the taste quality of cucumber after double-root grafting was poor. Wang et al. (2019) found that compared with conventional grafting and self-rooting seedlings, the method of interstock grafting can significantly increase the types and contents of volatile substances in cucumber fruits. Besides, bagging was also an effective measure to improve the fruit quality. Shan et al. (2020) demonstrated that cucumber fruits were found to have enhanced fruit flavor 


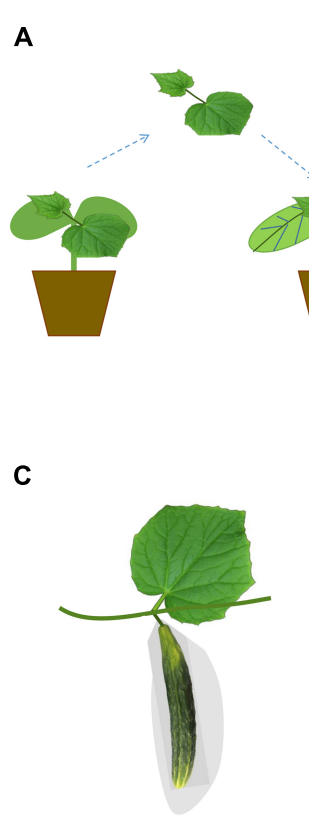

\section{B}
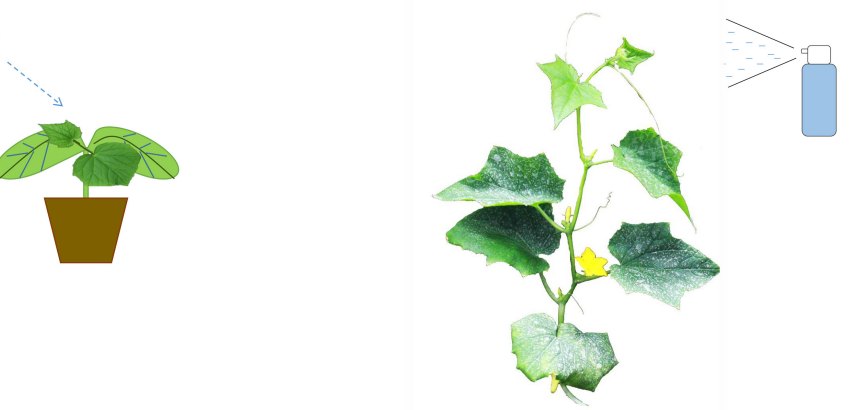

FIGURE 2 | Illustration of the cultivation techniques in cucumber fruit quality breeding. Grafting technique (A), application of exogenous fertilizers and growth regulators (B), and bagging technology (C) are widely used in cucumber fruit quality breeding.

quality after bagging, for the elevated relative proportion of 66 aldehyde, (E,Z)-2,6-nonadienal/(E)-2-nonenal ratio, and linoleic/ $\alpha$-linolenic acid ratio.

\section{Physiological Regulation of Nutrient Quality in Cucumber}

Grafting also has an influence on nutrient qualities in cucumber fruits. For example, in the study of Zhao et al. (2018) when cucumber was grafted onto "Weisheng NO.1," the soluble solid content in the fruit was significantly higher than that of the self-grafted group. Besides, the contents of the sugar, organic acids, amino acids, and alcohols were greatly increased when grafting "xintaimici" cucumber on the "GNo.45" pumpkin (Cucurbita moschata) (Miao et al., 2019). Dong et al. (2018) also found that elevated carbon dioxide $\left(\mathrm{CO}_{2}\right)$ concentration and high nitrogen $(\mathrm{N})$ application can also increase the content of nutrients such as fructose and glucose in cucumber by promoting the carbon translocation from source leaves to fruits. Qian et al. (2018) also found that gibberellin GA4 + 7 treatment improved the nutrient quality in cucumber fruits but decreased its commercial quality. On the contrary, CPPU treatment had a negative effect on the nutritional quality of cucumber (Qian et al., 2018). Moreover, He et al. (2018) found that exogenous calcium treatment on cucumbers under hypoxic stress results in an increased soluble sugar content in cucumber fruits so that enhances its nutrient quality. Ali et al. (2019) found that cucumber growth can be improved by adding arbuscular mycorrhizal strain (AM: Glomus versiforme L.) inoculant with organic substrates (GS), and GS + AMF (arbuscular mycorrhizal fungi) treatments increase the total soluble solids of cucumber fruits and soluble sugar content, thereby improving the nutrient qualities of cucumber fruits. With the rapid development of facility cultivation technology, cucumber has now become one of the main crops cultivated in protected areas. Di-n-butyl phthalate (DBP) is widely used as a plasticizer in plastic films because it can increase the toughness and elasticity of products. However, one of its main components, dibromophenol, can cause agricultural pollution that leads to food safety problems, and it has been widely concerned (Heudorf et al., 2007). DBP stress has also a detrimental effect on the contents of organic acids, vitamin C, soluble protein, and soluble sugar in cucumber fruits and resulted in the residue of dibromophenol under protected cultivation conditions. Although the residual dibromophenol in cucumber fruits is below the risk threshold, the potential health risks cannot be ignored (Wang et al., 2016). Therefore, in the process of studying cucumbers, attention should also be paid to the safety of the protected cultivation of cucumbers.

\section{PERSPECTIVE}

Compared to the traditional model plants such as Arabidopsis and rice, cucumber has some advantages as a new model plant for studies on gene function during fruit development. However, the fruit development of cucumber is a complex biological process, which is affected both by internal genes and external environmental factors. We still need firstly a comprehensive understanding of cucumber quality traits and problems of cultivation skills such as the production of grafted rootstocks, genetic deterioration in breeding, and soil renovation under protected cultivation. Then, we should analyze the compositions of good-quality fruits, such as the types and content of flavor substances, the nutrients, and pigments in cucumber fruits by using high-throughput, high-resolution, and high-sensitivity 
modern instrumental analysis methods. Combining with the taste evaluation system of consumers, the breeding goal of cucumber flavor quality can be established and then the genetic mechanism of formation of cucumber fruit quality can be explored. Molecular breeding techniques and methods are used to create new varieties with the best commercial quality (the top flower with thorns and straight strips), nutritional quality (rich in nutrients), and flavor quality (clear fragrance and no bitterness) to meet consumer demand eventually.

In recent years, biotechnologies such as fine mapping, cloning, and transgenesis of genes for important cucumber fruit traits have developed rapidly, and molecular markers combined with traditional breeding methods have been widely used. We will accelerate the completion of the improvement of fruit quality and achieve the breeding goal of high quality, high yield, and stable yield in cucumber fruit production.

\section{REFERENCES}

Ali, A., Ghani, M. I., Ding, H., Fan, Y., Cheng, Z., and Iqbal, M. (2019). Co-amended synergistic Interactions between arbuscular mycorrhizal fungi and the organic substrate-induced cucumber yield and fruit quality associated with the regulation of the AM-Fungal community structure under anthropogenic cultivated soil. Int. J. Mol. Sci. 20:1539. doi: 10.3390/ijms2007 1539

Andeweg, J. M., and Bruyn, J. (1959). Breeding of non-bitter cucumbers. Euphytica 8, 13-20. doi: 10.1007/BF00022084

Balkema-Boomstra, A. G., Zijlstra, S., Verstappen, F. W. A., Inggamer, H., Mercke, P. E., Jongsma, M. A., et al. (2003). Role of cucurbitacin C in resistance to spider mite (Tetranychus urticae) in Cucumber ( Cucumis sativus L.). J. Chem. Ecol. 29, 225-235. doi: 10.1023/A:1021945101308

Beaulieu, J. C., and Lea, J. M. (2006). Quality changes in cantaloupe during growth, maturation, and in stored fresh-cut cubes prepared from fruit harvested at various maturities. J. Am. Soc. Hortic. Sci. 132, 127-139. doi: 10.1007/s10658007-9180-2

Bo, K., Ma, Z., Chen, J., and Weng, Y. (2015). Molecular mapping reveals structural rearrangements and quantitative trait loci underlying traits with local adaptation in semi-wild Xishuangbanna cucumber ( Cucumis sativus L. var. xishuangbannanesis Qi et Yuan). Theor. Appl. Genet. 128, 25-39. doi: 10.1007/ s00122-014-2410-z

Bo, K., Song, H., Shen, J., Qian, C., Staub, J. E., Simon, P. W., et al. (2012). Inheritance and mapping of the ore gene controlling the quantity of $\beta$-carotene in cucumber (Cucumis sativus L.) endocarp. Mol. Breed. 30, 335-344. doi: 10.1007/s11032-011-9624-4

Bo, K., Wei, S., Wang, W., Miao, H., Dong, S., Zhang, S., et al. (2019). QTL mapping and genome-wide association study reveal two novel loci associated with green flesh color in cucumber. BMC Plant Biol. 19:243. doi: 10.1186/s12870-0191835-6

Boualem, A., Troadec, C., Camps, C., Lemhemdi, A., Morin, H., Sari, M.-A., et al. (2015). A cucurbit androecy gene reveals how unisexual flowers develop and dioecy emerges. Science 350, 688-691. doi: 10.1126/science.aac8370

Boualem, A., Troadec, C., Kovalski, I., Sari, M.-A., Perl-Treves, R., and Bendahmane, A. (2009). A conserved ethylene biosynthesis enzyme leads to andromonoecy in two cucumis species. PLoS One 4:e6144. doi: 10.1371/journal. pone.0006144

Che, G., Gu, R., Zhao, J., Liu, X., Song, X., Zi, H., et al. (2020). Gene regulatory network controlling carpel number variation in cucumber. Development 147:dev184788. doi: 10.1242/dev.184788

Chen, C., Liu, M., Jiang, L., Liu, X., Zhao, J., Yan, S., et al. (2014). Transcriptome profiling reveals roles of meristem regulators and polarity genes during fruit trichome development in cucumber (Cucumis sativus L.). J. Exp. Botany 65, 4943-4958. doi: 10.1093/jxb/eru258

Chen, S., Zhang, R., Hao, L., Chen, W., and Cheng, S. (2015). Profiling of volatile compounds and associated gene expression and enzyme activity during fruit

\section{AUTHOR CONTRIBUTIONS}

CY, JZ, JY, and HW conceived the review, conducted the literature review, and wrote the manuscript. CW and TL collected the literature. SF provided critical comments on the manuscript. All authors read and approved the manuscript.

\section{FUNDING}

This study was supported by the National Key Research and Development Program of China (2018YFD1000800 and 2019YFD1000300), Natural Science Foundation of Zhejiang Province (LY21C150002), and National Natural Science Foundation of China (Grant Nos. 31872105, 31972221, 32002048, and 31801862).

development in two cucumber cultivars. PLoS One 10:e0119444. doi: 10.1371/ journal.pone.0119444

Cheng, Z., Gu, X., Zhang, S., Miao, H., Zhang, R., Liu, M., et al. (2010). QTL analysis for fruit length of cucumber. China Vegetables 12, 20-25.

Choi, E., Kim, B., Hwang, U., Han, W., and Dong, H. (2013). Characterization of blooming on cucumber fruits. Korean J. Hortic. Sci. Technol. 31, 159-164. doi: 10.7235/hort.2013.12160

Colla, G., Rouphael, Y., Jawad, R., Kumar, P., Rea, E., and Cardarelli, M. (2013). The effectiveness of grafting to improve $\mathrm{NaCl}$ and $\mathrm{CaCl} 2$ tolerance in cucumber. Sci. Hortic. 164, 380-391. doi: 10.1016/j.scienta.2013.09.023

Cuevas, H. E., Song, H., Staub, J. E., and Simon, P. W. (2010). Inheritance of beta-carotene-associated flesh color in cucumber (Cucumis sativus L.) fruit. Euphytica 171, 301-311. doi: 10.1007/s10681-009-0017-2

Dong, J., Xu, Q., Gruda, N., Chu, W., Li, X., and Duan, Z. (2018). Elevated and super-elevated $\mathrm{CO} 2$ differ in their interactive effects with nitrogen availability on fruit yield and quality of cucumber. J. Sci. Food Agric. 98, 4509-4516. doi: $10.1002 /$ jsfa. 8976

Dong, S., Cao, L., Zhang, S., Wang, G., Miao, H., Xie, B., et al. (2013). Effect of grafting on fruit appearance quality and flavor substances in cucumber. China Vegetables 22, 44-51.

Dong, S., Miao, H., Zhang, S., Liu, M., Wang, Y., and Gu, X. (2012). Genetic analysis and gene mapping of white fruit skin in cucumber (Cucumis sativus L.). Acta Botanica Boreali-Occidentalia Sin. 32, 2177-2181. doi: 10.1007/s11783011-0280-z

Egea, I., Barsan, C., Bian, W., Purgatto, E., Latché, A., Chervin, C., et al. (2010). Chromoplast differentiation: current status and perspectives. Plant Cell Physiol. 51, 1601-1611. doi: 10.1093/pcp/pcq136

Forss, D., Dunstone, E., Ramshaw, E., and Stark, W. (1962). The flavor of cucumbers. J. Food Sci. 27, 90-93. doi: 10.1111/j.1365-2621.1962.tb00064.x

$\mathrm{Gu}, \mathrm{X}$., Zhang, S., Guo, Y., and Xu, C. (2004). Inheritance of bitterness in cucumber. Acta Hortic. Sin. 31, 613-616.

Hao, L., Chen, S., Wang, C., Chen, Q., Wan, X., Shen, X., et al. (2013). Aroma components and their contents in cucumbers from different genotypes. J. Northwest A F Univ. 41, 139-146. doi: 10.13207/j.cnki.jnwafu.2013.06.027

Hao, N., Du, Y., Li, H., Wang, C., Wang, C., Gong, S., et al. (2018). CsMYB36 is involved in the formation of yellow green peel in cucumber (Cucumis sativus L.). Theor. Appl. Genet. 131, 1659-1669. doi: 10.1007/s00122-018-3105-7

Hatanaka, A., Kajiwara, T., and Harada, T. (1975). Biosynthetic pathway of cucumber alcohol: trans-2,cis-6-nonadienol via cis-3,cis-6-nonadienal. Phytochemistry 14, 2589-2592. doi: 10.1016/0031-9422(75)85230-7

He, L., Li, Y., Li, B., Du, N., and Guo, S. (2018). The effect of exogenous calcium on cucumber fruit quality, photosynthesis, chlorophyll fluorescence, and fast chlorophyll fluorescence during the fruiting period under hypoxic stress. BMC Plant Biol. 18:180. doi: 10.1186/s12870-018-1393-3

Heudorf, U., Mersch-Sundermann, V., and Angerer, J. (2007). Phthalates: toxicology and exposure. Int. J. Hygiene Environ. Health 210, 623-634. doi: 10.1016/j.ijheh.2007.07.011 
Horvath, D. P., Schaffer, R., West, M., and Wisman, E. (2003). Arabidopsis microarrays identify conserved and differentially expressed genes involved in shoot growth and development from distantly related plant species. Plant J. 34, 125-134. doi: 10.1046/j.1365-313X.2003.01706.x

Huang, S., Li, R., Zhang, Z., Li, L., Gu, X., Fan, W., et al. (2009). The genome of the cucumber, Cucumis sativus L. Nat. Genet. 41, 1275-1281. doi: 10.1038/ng.475

Jiang, L., Yan, S., Yang, W., Li, Y., Xia, M., Chen, Z., et al. (2015). Transcriptomic analysis reveals the roles of microtubule-related genes and transcription factors in fruit length regulation in cucumber (Cucumis sativus L.). Sci. Rep. 5, 207-228. doi: $10.1038 /$ srep 08031

Kamachi, S., Sekimoto, H., Kondo, N., and Sakai, S. (1997). Cloning of a cDNA for a 1-aminocyclopropane-1-carboxylate synthase that is expressed during development of female flowers at the apices of Cucumis sativus L. Plant Cell Physiol. 38, 1197-1206. doi: 10.1093/oxfordjournals.pcp.a029106

Kemp, T., Knavel, D., and Stoltz, L. (1974). Identification of some volatile compounds from cucumber. J. Agric. Food Chem. 22, 717-718. doi: 10.1021/ jf60194a006

King, S., Davis, A., Liu, W., and Levi, A. (2008). Grafting for Disease Resistance. HortScience 43, 1673-1676. doi: 10.21273/HORTSCI.43.6.1673

Knopf, R. R., and Trebitsh, T. (2006). The Female-Specific Cs-ACS1G Gene of Cucumber. A Case of Gene Duplication and Recombination between the Non-Sex-Specific 1-Aminocyclopropane-1-Carboxylate Synthase Gene and a Branched-Chain Amino Acid Transaminase Gene. Plant Cell Physiol. 47, 12171228. doi: $10.1093 / \mathrm{pcp} / \mathrm{pcj} 09$

Kooistra, E. (1971). Inheritance of fruit flesh and skin colours in powdery mildew resistant cucumbers (Cucumis Sativus L.). Euphytica 20, 521-523. doi: 10.1007/ BF00034206

Lee, J. (1994). Cultivation of Grafted Vegetables I. Current Status, Grafting Methods, and Benefits. Hortscience 29, 235-239. doi: 10.21273/HORTSCI.29. 4.235

Li, Y., Wen, C., and Weng, Y. (2013). Fine mapping of the pleiotropic locus $B$ for black spine and orange mature fruit color in cucumber identifies a $50 \mathrm{~kb}$ region containing a R2R3-MYB transcription factor. Theor. Appl. Genet. 126, 2187-2196. doi: 10.1007/s00122-013-2128-3

Li, Z., Huang, S., Liu, S., Pan, J., Zhang, Z., Tao, Q., et al. (2009). Molecular isolation of the $M$ gene suggests that a conserved-residue conversion induces the formation of bisexual flowers in cucumber plants. Genetics 182, 1381-1385. doi: 10.1534/genetics.109.104737

Ligor, T., and Buszewski, B. (2008). Single-drop microextraction and gas chromatography-mass spectrometry for the determination of volatile aldehydes in fresh cucumbers. Anal. Bioanal. Chem. 391, 2283-2289. doi: 10.1007/s00216008-2098-5

Liu, H., Jiao, J., Liang, X., Liu, J., Meng, H., Chen, S., et al. (2016). Map-based cloning, identification and characterization of the $w$ gene controlling white immature fruit color in cucumber (Cucumis sativus L.). Theor. Appl. Genet. 129, 1247-1256. doi: 10.1007/s00122-016-2700-8

Liu, X., Ezra, B., Cai, Y., and Ren, H. (2016). Trichome-related mutants provide a new perspective on multicellular trichome initiation and development in cucumber (Cucumis sativus L). Front. Plant Sci. 7:1187. doi: 10.3389/fpls.2016. 01187

Liu, M. (2018). Preliminary Functional Analysis of Cucumber Lipoxygenase CsLOX2 Involved in the Synthesis of C9 Aldehydes. Xianyang: Northwest A\&F University.

Liu, X., Wang, T., Ezra, B., Kezia, B., Dong, M., Zhang, Y., et al. (2018). Comprehensive analysis of NAC transcription factors and their expression during fruit spine development in cucumber (Cucumis sativus L.). Hortic. Res. 5:31. doi: 10.1038/s41438-018-0036-z

Lu, H., Miao, H., Tian, G., Wehner, T., Gu, X., and Zhang, S. (2015). Molecular mapping and candidate gene analysis for yellow fruit flesh in cucumber. Mol. Breed. 35, 1-8. doi: 10.1007/s11032-015-0263-z

Lun, Y., Wang, X., Zhang, C., Yang, L., Gao, D., Chen, H., et al. (2016). A CsYcf54 variant conferring light green coloration in cucumber. Euphytica 208, 509-517. doi: 10.1007/s10681-015-1592-z

Lv, J., Li, M., Qian, W., and Qi, W. (1992). Vegetable quality, criterion and sensory identification. J. Changjiang Vegetables 6, 3-5.

Malundo, T., Shewfelt, R., and Scott, J. (1995). Flavor quality of fresh tomato (Lycopersicon esculentum Mill.) as affected by sugar and acid levels. Postharvest Biol. Technol. 6, 103-110. doi: 10.1016/0925-5214(94)00052-T
Miao, L., Di, Q., Sun, T., Li, Y., and Yu, X. (2019). Integrated metabolome and transcriptome analysis provide insights into the effects of grafting on fruit flavor of cucumber with different rootstocks. Int. J. Mol. Sci. 20, 289-302. doi: $10.3390 / \mathrm{ijms} 20143592$

Ohara, T., Sugiyama, M., and Sakata, Y. (2006). The history of melon and cucumber grafting in Japan. Acta Hortic. 767, 217-228. doi: 10.17660/ActaHortic.2008. 767.22

Palma-Harris, C., Mcfeeters, R., and Fleming, H. (2001). Solid-phase microextraction (SPME) technique for measurement of generation of fresh cucumber flavor compounds. J. Agric. Food Chem. 49, 4203-4207. doi: 10.1021/jf010182w

Pan, Y., Qu, S., Bo, K., Gao, M., Haider, K. R., and Weng, Y. (2017). QTL mapping of domestication and diversifying selection related traits in round-fruited semiwild Xishuangbanna cucumber (Cucumis sativus L. var. xishuangbannanesis). Theor. Appl. Genet. 130, 1531-1548. doi: 10.1007/s00122-017-2908-2

Peng, X., Chen, Z., Shi, F., Wu, X., Wang, Y., and Gao, L. (2010). Effects of different grafting methods on growth and fruit quality of cucumber in solar greenhouse. Northern Hortic. 15, 122-124.

Pérez, A. G., Olías, R., Luaces, P., and Sanz, C. (2002). Biosynthesis of strawberry aroma compounds through amino acid metabolism. J. Agric. Food Chem. 50, 4037-4042. doi: 10.1021/jf011465r

Pierce, L., and Wehner, T. (1990). Review of genes and linkage groups in cucumber. Hortic. Sci. 25, 605-615. doi: 10.1016/0304-4238(90)90105-N

Pramnoi, P., Somta, P., Chankaew, S., Juwattansomran, R., and Srinives, P. (2013). A single recessive gene controls fragrance in cucumber (Cucumis sativus L.). J. Genet. 92, 147-149. doi: 10.1007/s12041-013-0228-0

Qi, J., Liu, X., Shen, D., Miao, H., Xie, B., Li, X., et al. (2013). A genomic variation map provides insights into the genetic basis of cucumber domestication and diversity. Nat. Genet. 45, 1510-1515. doi: 10.1038/ng.2801

Qian, C., Ren, N., Wang, J., Xu, Q., Chen, X., and Qi, X. (2018). Effects of exogenous application of CPPU, NAA and $\mathrm{GA}_{4+7}$ on parthenocarpy and fruit quality in cucumber (Cucumis sativus L.). Food Chem. 243, 410-413. doi: 10.1016/j. foodchem.2017.09.150

Qiao, H., Zhu, F., Li, C., and Zhang, H. (2005). Inherited analysis on nutrient quality character of cucumber. J. Northeast Agric. Univ. 36, 290-293. doi: 10. 19720/j.cnki.issn.1005-9369.2005.03.008

Rice, C., Rymal, K., Chambliss, O., and Johnson, F. (1981). Chromatographic and mass spectral analysis of cucurbitacins of three Cucumis sativus cultivars. J. Agric. Food Chem. 29, 194-196. doi: 10.1021/jf00103a051

Samuels, L., Kunst, L., and Jetter, R. (2008). Sealing plant surfaces: cuticular wax formation by epidermal cells. Ann. Rev. Plant Biol. 59, 683-707. doi: 10.1146/ ANNUREV.ARPLANT.59.103006.093219

Schieberle, P., Ofner, S., and Grosch, W. (1990). Evaluation of potent odorants in cucumbers (Cucumis sativus) and muskmelons (Cucumis melo) by aroma extract dilution analysis. J. Food Sci. 55, 193-195. doi: 10.1111/j.1365-2621. 1990.tb06050.x

Sebastian, P., Schaefer, H., Telford, I., and Renner, S. (2010). Cucumber (Cucumis sativus) and melon (C. melo) have numerous wild relatives in Asia and Australia, and the sister species of melon is from Australia. Proc. Natl. Acad. Sci. U. S. A. 107, 14269-14273. doi: 10.1073/pnas.1005338107

Shan, N., Gan, Z., Nie, J., Liu, H., Wang, Z., and Sui, X. (2020). Comprehensive characterization of fruit volatiles and nutritional quality of three cucumber (Cucumis sativus L.) genotypes from different geographic groups after bagging treatment. Foods 9:294. doi: 10.3390/foods9030294

Shang, Y., Ma, Y., Zhou, Y., Zhang, H., Duan, L., Chen, H., et al. (2014). Biosynthesis, regulation, and domestication of bitterness in cucumber. Science 346, 1084-1088. doi: 10.1126/science. 1259215

Tan, J., Tao, Q., Niu, H., Zhang, Z., Li, D., Gong, Z., et al. (2015). A novel allele of monoecious $(m)$ locus is responsible for elongated fruit shape and perfect flowers in cucumber (Cucumis sativus L.). Theor. Appl. Genet. 128, 2483-2493. doi: 10.1007/s00122-015-2603-0

Wang, G., Qin, Z., Zhou, X., and Zhao, Z. (2007). Genetic analysis and SSR markers of tuberculate trait in Cucumis sativus. Chin. Bull. Botany 24, 168-172.

Wang, J., Li, X., Wang, H., Qiu, Y., Song, J., Zhang, X., et al. (2012). Molecular cloning and expression analysis of $\zeta$-carotene desaturase gene from Cucumis sativus L. Mol. Plant Breed. 10, 520-527. doi: 10.3969/mpb.010.000520 
Wang, L., Dong, Y., Sun, X., and Liu, S. (2019). Effects of different grafting methods and different interstock graftings on fruit quality and volatile compounds in cucumber. Plant Physiol. J. 55, 867-874. doi: 10.13592/j.cnki.ppj.2018.0469

Wang, L., Sun, X., Chang, Q., Tao, Y., Wang, L., Dong, J., et al. (2016). Effect of di-n-butyl phthalate (DBP) on the fruit quality of cucumber and the health risk. Environ. Sci. Pollut. Res. 23, 24298-24304. doi: 10.1007/s11356-016-7658- 1

Wang, M., Liu, S., Zhang, S., Miao, H., Wang, Y., Tian, G., et al. (2014). Quantitative trait loci associated with fruit length and stalk length in cucumber using RIL population. Acta Botanica Boreali-Occidentalia Sin. 34, 1764-1770.

Wang, W., Zhang, Y., Xu, C., Ren, J., Liu, X., Black, K., et al. (2015). Cucumber ECERIFERUM1 (CsCER1), which influences the cuticle properties and drought tolerance of cucumber, plays a key role in VLC alkanes biosynthesis. Plant Mol. Biol. 87, 219-233. doi: 10.1007/s11103-014-0271-0

Wehner, T., Shetty, N., and Walters, S. (2001). Segregation and linkage of several genes in cucumber. J. Am. Soc. Hortic. Sci. 126, 442-450.

Wei, G., Tian, P., Zhang, F., Qin, H., Miao, H., Chen, Q., et al. (2016). Integrative analyses of nontargeted volatile profiling and transcriptome data provide molecular insight into VOC diversity in cucumber plants (Cucumis sativus). Plant Physiol. 172, 603-618. doi: 10.1104/pp.16.01051

Wei, W. (2018). Preliminary Study on the Role of Hydroperoxide lyase CsHPLs in the Function of Aldehydes Aroma Synthesis in Cucumber. Xianyang: Northwest A\&F University.

Wenzel, G., Kennard, W., and Havey, M. (1995). Quantitative trait analysis of fruit quality in cucumber: QTL detection, confirmation, and comparison with mating-design variation. Theor. Appl. Genet. 91, 53-61. doi: 10.1007/ bf00220858

Whalen, M. (2005). Host defence in a developmental context. Mol. Plant Pathol. 6, 347-360. doi: 10.1111/j.1364-3703.2005.00286.x

Xu, Q., Chen, X., Yu, J., Li, L., and Cao, B. (2001). Preliminary study on heritability and genetic correlation of quality characters in pickling cucumber (Cucumis sativus L.). Jiangsu Agric. Res. 22, 18-20.

Xu, X., Lu, L., Zhu, B., Xu, Q., Qi, X., and Chen, X. (2015). QTL mapping of cucumber fruit flesh thickness by SLAF-seq. Sci. Rep. 5, 895-906. doi: 10.1038/ srep15829

Xu, X., Pan, J., He, M., Tian, H., Qi, X., Xu, Q., et al. (2019a). Transcriptome profiling reveals key genes related to astringency during cucumber fruit development. 3 Biotech 9, 390-398. doi: 10.1007/s13205-019-1922-2

Xu, X., Tian, H., He, M., Gebretsadik, K., Qi, X., Xu, Q., et al. (2019b). Changes in catechin contents and expression of catechin biosynthesis-associated genes during early cucumber fruit development. Acta Physiol. Plant. 41, 130-138. doi: 10.1007/s11738-019-2925-7

Yang, L., Koo, D.-H., Li, Y., Zhang, X., Luan, F., Havey, M. J., et al. (2012). Chromosome rearrangements during domestication of cucumber as revealed by high-density genetic mapping and draft genome assembly. Plant J. 71, 895-906. doi: 10.1111/j.1365-313x.2012.05017.x

Yang, S., Cai, Y., Liu, X., Dong, M., Zhang, Y., Chen, S., et al. (2018). A CsMYB6CsTRY module regulates fruit trichome initiation in cucumber. J. Exp. Bot. 69, 1887-1902. doi: 10.1093/jxb/ery047

Yuan, X., Pan, J., Cai, R., Guan, Y., Liu, L., Zhang, W., et al. (2008). Genetic mapping and QTL analysis of fruit and flower related traits in cucumber (Cucumis sativus L.) using recombinant inbred lines. Euphytica 164, 473-491. doi: 10.1007/s10681-008-9722-5

Yundaeng, C., Somta, P., Tangphatsornruang, S., Chankaew, S., and Srinives, P. (2015). A single base substitution in BADH/AMADH is responsible for fragrance in cucumber (Cucumis sativus L.), and development of SNAP markers for the fragrance. Theor. Appl. Genet. 128, 1881-1892. doi: 10.1007/s00122-0152554-5

Zhang, C., Win, K. T., Kim, Y.-C., and Lee, S. (2019). Two types of mutations in the HEUKCHEEM gene functioning in cucumber spine color development can be used as signatures for cucumber domestication. Planta 250, 1491-1504. doi: 10.1007/s00425-019-03244-w

Zhang, J., Yang, J., Luo, J., Zheng, X., Wen, C., and Xu, Y. (2019). Transcription factor CsWIN1 regulates pericarp wax biosynthesis in cucumber grafted on pumpkin. Front. Plant Sci. 10:1564. doi: 10.3389/fpls.2019.01564

Zhang, K., Song, H., Kai-Liang, B., Ji, L., Zheng, M., Lou, Q., et al. (2015). QTL Mapping of Multi-Locule-Number Trait in Xishuangbanna Cucumber. Sci. Agric. Sin. 48, 3211-3220.

Zhang, S., Liu, S., Miao, H., Wang, M., Liu, P., Wehner, T. C., et al. (2016). Molecular mapping and candidate gene analysis for numerous spines on the fruit of cucumber. J. Heredity 107, 471-477. doi: 10.1093/jhered/esw028

Zhang, S., Miao, H., Sun, R., Wang, X., Huang, S., Wehner, T., et al. (2013). Localization of a new gene for bitterness in cucumber. J. Heredity 104, 134-139. doi: 10.1093/jhered/ess075

Zhang, X., Zhang, B., Liu, L., and Liu, Z. (2020). Correlation analysis between main fruit characters and quality characters of South China type cucumber. Hubei Agric. Sci. 59, 389-391. doi: 10.14088/j.cnki.issn0439-8114.2020.S1.106

Zhao, J., Jiang, L., Che, G., Pan, Y., Li, Y., Hou, Y., et al. (2019). A functional allele of CsFUL1 regulates fruit length through repressing CsSUP and inhibiting auxin transport in cucumber. Plant Cell 31, 1289-1307. doi: 10.1105/tpc.18.00905

Zhao, L., Liu, A., Song, T., Jin, Y., Xu, X., Gao, Y., et al. (2018). Transcriptome analysis reveals the effects of grafting on sugar and $\alpha$-linolenic acid metabolisms in fruits of cucumber with two different rootstocks. Plant Physiol. Biochem. 130, 289-302. doi: 10.1016/j.plaphy.2018.07.008

Zhou, Q., Wang, S., Hu, B., Chen, H., Zhang, Z., and Huang, S. (2015). An ACCUMULATION AND REPLICATION OF CHLOROPLASTS 5 gene mutation confers light green peel in cucumber. J. Integr. Plant Biol. 57, 936-942. doi: $10.1111 /$ jipb.12355

Zhou, Y., Ma, Y., Zeng, J., Duan, L., Xue, X., Wang, H., et al. (2016). Convergence and divergence of bitterness biosynthesis and regulation in Cucurbitaceae. Nat. Plants 2, 1251-1263. doi: 10.1038/nplants.2016.183

Conflict of Interest: The authors declare that the research was conducted in the absence of any commercial or financial relationships that could be construed as a potential conflict of interest.

Publisher's Note: All claims expressed in this article are solely those of the authors and do not necessarily represent those of their affiliated organizations, or those of the publisher, the editors and the reviewers. Any product that may be evaluated in this article, or claim that may be made by its manufacturer, is not guaranteed or endorsed by the publisher.

Copyright (C) 2021 Zhang, Feng, Yuan, Wang, Lu, Wang and Yu. This is an openaccess article distributed under the terms of the Creative Commons Attribution License (CC BY). The use, distribution or reproduction in other forums is permitted, provided the original author(s) and the copyright owner(s) are credited and that the original publication in this journal is cited, in accordance with accepted academic practice. No use, distribution or reproduction is permitted which does not comply with these terms. 